Association between

ORMDL3, IL1RL1 and a deletion on chromosome $17 q 21$ with asthma risk in Australia

Manuel AR Ferreira, Allan F McRae, Sarah E Medland, Dale R Nyholt, Scott D Gordon, Margaret J Wright, Anjali K Henders, Pamela A Madden, Peter M Visscher, Naomi R Wray, Andrew C Heath, Grant W Montgomery, David L Duffy and Nicholas G Martin

European Journal of Human Genetics (2011) 19, 1109; doi:10.1038/ejhg.2011.92

Correction to: European Journal of Human Genetics (2011) 19, 458-464; doi:10.1038/ejhg.2010.191; published online 8 December 2010

Since the publication of the above paper, the authors have identified the following errors in the paper:

'We found no evidence for additional independent risk variants in this region (not shown), consistent with Moffatt et al, should instead read: 'We found evidence for additional independent risk variants in this region (not shown), consistent with Moffatt et al, and in the conclusion, 'ORMDL1' should read 'ORMDL3'.

The authors wish to apologise for these errors.

\section{A dominant mutation in RPE65 identified by whole-exome sequencing causes retinitis pigmentosa with choroidal involvement}

Sara J Bowne, Marian M Humphries, Lori S Sullivan, Paul F Kenna, Lawrence CS Tam, Anna S Kiang, Matthew Campbell, George M Weinstock, Daniel C Koboldt, Li Ding, Robert S Fulton, Erica J Sodergren, Denis Allman, Sophia Millington-Ward, Arpad Palfi, Alex McKee, Susan H Blanton, Susan Slifer, Ioanna Konidari, G Jane Farrar, Stephen P Daiger and Peter Humphries

European Journal of Human Genetics (2011) 19, 1109; doi:10.1038/ejhg.2011.132

Correction to: European Journal of Human Genetics (2011) 19, 1074-1081; doi: 10.1038/ejhg.2011.86; published online 8 June 2011

It has come to the authors' attention that a reference was omitted from the above article under the Results subsection, Protein Analysis (page 7), where, at the end of this section, after the words 'bladeVII of the mutant protein', there should be a reference to:

Kiser PD, Golczak M, Lodowski DT, Chance MR, Palczewski K: Crystal structure of native RPE65, the retinoid isomerase of the visual cycle. Proc Natl Acad Sci USA 2009; 106: 17325-17330. 